$\mathrm{XXIX}$

\title{
THE MASSACRE OF THE TONSIL.*
}

\author{
By John N. MACKEnzIE, M. D.,
}

DALTMORL:.

During the past few years I have been repeatedly urged by medical friends to give some public utterance by way of formal protest against the indiscriminate and wholesale destruction and removal of the tonsils, which, far above all others, is the chief and most glaring abuse in the laryngology of the present day. They have been good enough to say that a word might not be amiss from one who has been through the dust and heat of the conflict that has raged around this and other fancies in surgical laryngology which have risen and fallen during the quarter of a century that has just passed away.

One of these friencls, a distinguisherl general surgeon of wide experience, large practice and exceptionally high professional skill, in insisting that I say something on the subject. gave me as his deliberate opinion that of all the surgical insanities within his recollection this onslanght on the tonsils was the worst, not excepting the operation on the appendix. And, indeed, when I look back through an experience of over thirty years, in which I have seen theory after theory, for some of which I have been partially, if not wholly, responsible myself, come and go, materialize and dissolve, I feel that, notwithstanding the fact that I approach the subject with reluctance, with diffidence, with hesitancy-with even timidity, and fully mindful of the truth that we are all liable to error, even the youngest of us, and that rowadays in some quarters apparently age and experience count for nothing. I feel I may be pardoned for saying a few words in what I consider to be the interest of the public health, and, therefore, of the public safety.

* Read April 24, 1912, before the Medical and Chirurgical Faculty of Maryland. 
Let me at the outset be not misunderstood. It is not my object to stir up strife, to impute unworthy motives to anyone, or to arrogate to myself any superior wisdom in the surgical management of tonsil disease.

Nor do I wish to shift to other shoulders all the blame. I, too, in my earlier days, have fallen by the way. Indeed, it was once facetiously said that the street in front of my office was paved with the turbinated bones of my victims.

That there are a host of conditions that call for more or less complete destruction of the tonsil is an axiomatic proposition which is not open to discussion. We have all been taking out tonsils for innumerable reasons ever since we entered our special field of work and we will continue to do so when proper occasion demands it. My contention is simply this, that in selecting our cases for operation we should be guided by a sane and safe conservatism and common sense, and not be carried away by those who, by their precept and example, are fast bringing our specialty into disrepute in the eyes of thoughtful and honorable men.

Many years ago Austin Flint was conducting an examination in physiology at the Bellevue Hospital Medical School in New York. Among the students who came up for graduation was a bright young fellow to whom Flint propounded the following conundrum: "What is the function of the spleen?" And the lad replied that the function of the spleen was to enlarge in malarial fever. To the next question: "What is the function of the tonsil?" the boy declared that the mission of the tonsil was to swell and suppurate in quinsy. "That will do," said Flint, "you have passed a perfect examination, for you know as much about the subject as I do myself." Long before, a distinguished medical luminary on the other side of the Atlantic had said that were he, like Frankenstein, to attempt the artificial construction of a man, he would leave the tonsils out. In other words, at that period, or, as a matter of fact, from a period as long back as memory can run, the tonsil was regarded as a perfectly useless appendage which cumbered the throat, and which, therefore, ought to be gotten rid of. Like its little neighbor, the uvula, it was sacrificed on every possible pretext or when the surgeon did not know what else to do. I remember, a long time ago, in a discussion on hemorrhage after tonsillotomy before a New York society, a 
distinguished laryngologist made the statement that he had removed without accident many thousands (I have forgotten the exact number) of tonsils- to which declaration an inquisitive, incredulous individual present, with a mathematical turn of mind, said he had made a calculation which showed that in order to have removed that many tonsils within the limit of an ordinary lifetime the operator would have to average a bushel a day.

This general extirpation of the consils that obtained in the early days of laryngology received a rude and jarring jolt when, in the last century, it was proclaimed that the tonsil was physiologically directly related to the virility of the male. According to this luminous conception, which owed its popularity chiefly to the teachings of no less a personage than Chassaignac, destruction or extirpation of the tonsil meant impairment or extinction of procreative power. This doctrine at once made tonsillotomy very unpopular among the male laity; but when the Homeric shock of the battle that raged round this burning question had subsided, and it had been found that there were no facts to support the alleged relationship, then the work of slaughtering the tonsils again went merrily on.

But never in the history of medicine has the lust for operation on the tonsils been as passionate as it is at the present time. It is not simply the surgical thirst from which we have all suffered in our earlier days, just as at a still earlier period we suffered from the measles; it is a mania, a madness, an obsession. It has infected not only the general profession, but also the laity. A leading laryngologist in one of our largest cities came to me with the humiliating confession that, although holding views hostile to its performance, he had been forced to do a tonsillectomy in every case in order to satisfy the popt1lar craze and to save his practice from destruction.

Today the laity, with or withont medical advice, insist on entire removal of the tonsil for almost every conceivable infirmity. If I had time to do so, I could tell you some, if they were not so serious, amusing stories in this connection.

I will only relate one. A few days ago a woman brought her little six-year-old daughter to me to know whether her tonsils ought to come ont. Her nasal and throat passages were normai. 
The child was in perfect physical condition and complained of nothing. I said to the mother, "Your baby is perfectly well, why do you want her tonsils out?" "Because she sometimes wets the bed."

In the annual reports of nearly all the special hospitals for diseases of the nose and throat the number of tonsil removals, as compared with all other operations on the upper air tract and its appendages, is simply appalling. In conspicuous and refreshing contrast to the usual narrative of these productions let me quote from the last report of a well-known children's hospital in this city these words of sanity and wisdom:

"A large and annually increasing number of cases apply for operation for hypertrophied tonsils, or for adenoids. Of these the adenoids practically all need and receive operation with benefit and without injury.

"The recent universal inspection of the throats of school children has revealed the fact that nearly all children at some time of life have more or less enlarged tonsils.

"That most of this is harmless if not actually physiologic, and that their removal in these cases is not only unnecessary but injurious to the proper development of the child is our conviction.

"The rarity of rheumatism or endocarditis in children, while nearly every child has enlarged tonsils, would indicate that their removal is only exceptionally advisable, unless they mechanically interfere with respiration, deglutition, or speech. When this is the case they are still best removed with the tonsillotome uness radical extirpation is necessary for other reasons."

I cannot more correctly express the general attitude on the matter than by quoting the words of Professor Swain of Yale University, in the admirable paper with which he opened the debate on the subject at the last meeting of the American Laryngological Association in Philadelphia :

"When an author speaks of his experience in upwards of 9000 cases, mentioning especially 3000 removed within the capsule within the last six or seven years, the only method which he thinks is really worth the while--he certainly has a right to speak as an expert in regard, at least, to methods. Also, it will be readily deduced that he felt in removing tonsils thus wholly he was not depriving the patients of anything 
important. When it is the practice in recent years of many operators all over the country to always enucleate the tonsils as completely as possible in all cases, either children or adults, as a routine procedure, it would certainly seem to argue that in general tonsils are better out than in. The question of relative size, appearance, healthiness of structure or any such matter is apparently never thought of. Remove, anyway, and dismiss the matter as not worthy of further consideration." And, again, "It is a most excellent condition of things to be operating laryngologist to a busy internist, who takes the entire responsibility of removal. Failure and success are alike credited against him, but it is a case of blissful inexactness which I consider deplorable."

Much wild and incontinent talk, for which their teachers are sometimes largely to blame, has poisoned the minds of the younger generation of operators and thrown the public into hysteria. Tonsillectomy, for example, is held out to them, not only as a sure cure for, but as an absolute prophylactic against rheumatism and heart disease. They are told that with the disappearance of the tonsil in man, these diseases will cease to exist. Parents bring nowadays their perfectly sound children to the laryngologist for tonsil removal in order to head off these affections. Tonsillectomy is recommender as a curative during the agony of acute articular rheumatism. But the origin of the latter disease has recently been traced to an infection of the nasal mucosa following operation. Tomorrow it will come from somewhere else. Those of us who are old enough to remember will recall the story of chorea. Years ago we found the cause of this affection in the nasal passages. When this view, after the usual struggle, had to be abandoned, it was suddenly ciscovered that the eye was the portal of entrance. Today it has been caught in the tonsil. If we exercise a little patience it will turn up soon in some other organ.

In considering the question of operation on the tonsils. and especially complete removal, we must face the following facts:

I. The functions of the tonsil are, in the present state of our knowledge, unknown.

Whether they are portals of entrance or avenues of exit for infection, whether they protect the organism from danger or invite the presence of disease, whether the pathogenic bac- 
teria sometimes found in them are coming out or going in, whether they are mantifacturers or storehouses of leuco-or lymphocytes, whether they represent the extreme outlying protective ramparts and that, therefore, their destruction would mean the removal of the battle line against infection from the throat to the neck lymphatics, whether the efferent current of lymph exceeds the afferent in volume or velocity, whether, which seems probable, there is an endless flow of lymph from their interior to the free surface, which, unchecked, prevents the entrance of germs from the surface and washes out impurities from within, whether the organ possesses an internal secretion, sui generis, or whether, in fine, the tonsil structure is in any way essential to the well-being of the individual, are questions which have as yet received no definite solution, but which are full of interest and furnish material for instructive discussion and debate. Until the functions of the tonsil are known the final word on its removal cannot be spoken.

II. Whatever its functions may be, and the production of leucocytes is undoubtedly one of them, the tonsil is not, as is generally taught and believed, a lymphatic gland.

The general ignorance of this fact has led to the useless sacrifice of thousands of tonsils, on the fallacious assumption that their functional activity may easily be replaced by the myriads of other lymphatic glands in the body. The physiologic integrity of the tonsil is of the utmost importance in infant and child life. The gland appears early in embryonic life (fourth month), attains maturity at the end of the first year of infancy, and at or about puberty tends to diminish in size. It does not develop as a lymphatic gland from a plexus of pre-existing lymph vessels in the mesothelium, but as an ingrowth of endothelium from the second branchial pouch and, therefore, in its origin must be classed with the thymus and the thyroid, the former originating from the third, the latter from the fourth, while the parathyroid takes its origin from the third and fourth branchial pouches, all by inbudding of the endothelial lining of the primitive pharynx. These anatomic facts have been recently emphasized by Gordon Wilson $^{2}$ of Chicago, who, in a careful study in comparative anatony, has shown from various relations which the tonsil shows to the pharynx that the tonsil secretes or excretes a substance into the pharynx. The tonsil is present in all mammals, with 
a few exceptions, notably the white rat, and its anatomic arrangement is such that no matter how concealed it may be by folds of membrane it always retains communication with the pharynx. Observations made in his laboratory on the carnivora show that in this genus the tonsil is often so protected by folds as to be invisible from the mouth; but there always exists a channel of communication. This is well shown in the lion, where the tonsil lies in an elliptical sac of considerable size, which is so placed that during certain movements of the pharynx the contents may be expelled into the back of the mouth. In other words, we have here a structure which plays a rôle of importance in early life, in addition to its production of lymphocytes, and which necessitates a close relation to the pharynx. This rôle may be of infinite value to the infant in his earliest days of life, but which, as he grows through childhood into manhood, he is able to dispense with.

Now, the first organ to manufacture or store leucocytes in embryonic life is the thymus gland (Jacobi). ${ }^{3}$ In view of the origin of the tonsil from the branchial pouch, is it not conceivable, as Jacobi suggests, that it may assume the rôle of the thymus after birth or when the latter gland ceases to functionate or disappears?

III. It is rarely possible to separate the tonsil from its neighborhood during the acute invasion or rapid progress of a microbic or toxic poison (Jacobi).

Years ago Jacobi called attention to the fact that in cases of membranous throat disease whenever the membrane is limited to the tonsil, there is little or no glandular swelling in the neighborhood. If the membrane extends from the tonsil to its neighborhood, or starts at a distance from the tonsil, neighboring lymphatics swell at once.

Again, the treatment of this neighborhood shows its effect almost immediately in the swollen glands. This is especially true of diphtheria, which, when limited to the tonsil, produces Iess adenitis and constitutional symptoms, and, therefore, is less dangerous. We all remember, too, in the days before antitoxin, how much graver the prognosis was when the membrane appeared in the nose and upper pharynx than when it appeared on the tonsils. Nearly every case died.

IV. The rôle of the tonsils as portals of infection, like all new doctrines in medicine, has been greatly exaggerated. To 
state that they are, in certain cases, the avenues through which pathogenic organisms reach other organs is simply to state an incontrovertible proposition, in the light of present-day research. But to make them responsible for the long iliad of woes which has been laid to their account is to remove the whole question from its legitimate place in the region of cold clinical fact into the atmosphere of fads and fancies. Some absorption takes place in and from the tonsil; but it is far less than that which occurs in the more abundant and receptive lymphatic structures of the nose and nasal pharynx. The tonsil, moreover, is not built anatomically as a gateway of infection. I have not time to go into a review of this interesting subject, but will simply quote, with some modification, from a summary by Faulkner, of Pittsburgh (Medical Record, July 9, 1910), based on an analysis of observations made by Most, Retterer, Labbé, Hodenpyl, Jacobi, Grober and others, and also refer you to a symposium on the subject of the nasopharyngeal lymphatics and their relation to other parts of the body by Hartz, Poli, Logan Turner and Broeckaert:*

"The faucial tonsils are peculiar organs. They possess an anatomic character different from other tonsils and other lymphatic tissues. They are innocent organs with functions chiefly confused by medical literature. Their blood supply is scant and they have almost no communication with the lymphatic system. *** Their crypts are lined by mucous membrane having the ordinary function of other mucous membranes so far as known. They are distinctly separated from the very active absorptive and bacteriolytic structures of the fatces, pharynx and nose. Their position is a segregated one. Their external deep surface is covered by a dense fibrous capsule which sometimes sends a network of fibrous tissue as outrunners along the tonsillar blood vessels (Hodenpyl), the tonsil contains a system of closed lymph canals in the follicles which do not open into the connective tissue reticulum (Retterer, confirmed by Hodenpyl), diphtheritic membrane confined to the tonsil is relatively innocent (Jacobi). There are no lymphatic sinuses around the tonsil and the nearby lymph current is less active than that of the pharynx at some distance (Labbé). And finally, injections made into the region of the tonsil (not even into the tonsil itself) do not spread like those made into other parts of the nasopharynx (Labbé, Retterer, Hodenpyl, Most and Jacobi)." 
Hart $z,{ }^{5}$ in reviewing the important experiments of Lenhardt, says: "These experiments would lead to the assumption that the tonsils are frequently infected secondarily to acute infection of the nose and the accessory cavities and the nasopharynx. * * * It is probable that every inflammation of the mucosa induces a swelling, often imperceptible, of the neighboring lymphatic glands of greater or less extent, which, acting as a protective mechanism, inhibits the development of the germ. To the tonsils, which have the function of an open lymphatic gland, may be ascribed a protecting infuence against the microorganisms which are ever present in the mouth and nasopharynx, acting, also, as a barrier against their invasion into the trachea and esophagus. On the other hand, it must be admitted that the tonsils are frequently the seat of primary inflammation, and that they are more susceptible to disease than other membranous structures in this region."

The question has two sides, a purely bacteriologic and a purely clinical one. If we consider the vast extent of the area through which infection can possibly take place, and if we follow the lead of experiment and that of the pure bacteriologist to its extreme limit and logical end, we may find that nothing short of the guillotine or the axe will insure the patient against absolute and certain immunity from infection through the throat.

On the other hand, when we consider the fact that there are constantly loitering around the oro- and nasopharynxthis region is the clubhouse of the streptococcus-a miscellaneous crowd of pathogenic bacteria, and when we consider the further fact that thousands of operations are done in these regions every day and necessarily without antiseptic precautions, is it not significant at least that we meet with so little sepsis following their performance?

The chief practical lesson to be drawn from the foregoing facts is that in cases in which the throat, and particularly the tonsils, is apparently the starting point of infection, it is mandatory to examine the entire upper air tract and not be content with appearances that are visible to the eye through the open month alone. How many stop their search for the cause at the tonsil and fail to explore the deeper parts of the pliarynx. the retronasal space, to say nothing of the nasal passages and 
accessory sinuses? This entire region must be reckoned with, and failure to do so has probably sent more than one to his grave. I know of a number of cases of fruitless removal of the tonsil which have only gotten relief when treatment was subsequently directed to the nasal cavities and postnasal space. Not to mention many others, I am forcibly reminded of a case of general poisoning and wrecked health in a young woman in whom I had thought I had traced the source of infection to an antrum maxillare empyema. As there was no escaping pus, my diagnosis was not accepted by the family and attendant, and $I$ was not even permitted to make an exploratory puncture. I am unable to say what operation, if any, was done, as she naturally passed out of my hands. But as she grew rapidly worse, and as the futility of the treatment became apparent, my advice was finally reluctantly and doubtfully taken, the antrum was opened, the fetid contents evacuated and the patient, tunder appropriate treatment, went on to speedy and complete recovery.

I could tell you, also, of cases in which the tonsil has been held responsible for the morbid condition, and has been partially or completely removed, in which relief has only been secured by the discovery and treatment of disease in the nose and retronasal space. And of far graver, far-reaching and deeper significance are cases of infection in which life has doubtlessly been sacrificed by clinging to the lazy and stupefying delusion that the tonsil is the sole portal of poisoning.

$V$. The hypertrophied lymphatic tissue of the vault of the pharynx (adenoids) does harm chiefly through obstruction. Restore normal respiration in the child, and in a large number of cases the tonsils will take care of themselves. Even if the glands shot1l! remain large, if they are giving no trouble, they may be safely left in situ, for as their growth does not go on pari passu with the growth of the rest of the pharynx, the time soon comes when they become inconspicuous in the fully developed fauces.

VI. The mere size of the tonsil is of itself no indication for removal except it be large enough or diseased sufficiently to interfere with respiration, speech, or deglutition, in which case it, or a sufficient portion, should be taken away without delay. A large tonsil does not mean necessarily a diseased tonsil, nor does a small tonsil always indicate a healthy organ. Tonsils 
apparently diseased may consist of normal tissue and, on the other hand, perfectly normal looking glands may be found pathologic microscopically. The tonsil may be greatly enlarged, may extend far down into the pharynx or be buried deeply in the palatine arcade and yet not interfere with the well-being of the individual. Such tonsils are the special prey of the tonsillectomist. If they are not interrupting function, they had best be left alone, for they are doing no harm. The change in anatomic relations after operation is often so great that function is crippled more after their complete removal than it was before. Moreover, it occasionally happens that the resurrection of a "buried" tonsil is followed by the burial of the patient.

VII. A most interesting and instructive part of this subject is the occurrence of tonsil disease, with or without cervical adenitis, from infection from the nasai passages (from pus cavities, operations, etc.) and the improper care of the teeth during dentition. Wright," of Boston, reports a remarkable series of 150 cases in which operation on the tonsils was deferred until after the eruption of the molars, not only in the six,' but in the twelve-year period, and when dentition had been completely accomplished the enlarged cervical lymphatic glands disappeared, together with the swelling of the tonsils.

The practical illuminating lesson of these observations is that if, in infancy and childhood, we pay more attention to the neglected nasal cavities and to the hygiene of the mouth and teeth, we will have less tonsil disease and fewer tonsil operations.

Tonsillitis not infrequently follows operations on the nasal cavities, especially if pus be present, or even after a cold in the head. Experimental work along this line would seem to indicate that infection takes place through the lymphatics. Thus, in the carefully conducted experiments of Lenhardt. ${ }^{7}$ it was found, among other things, that foreign matter, even when injected into the mucous membrane of one nasal passage, was found in both tonsils in a short time after the injection.

In the permanent removal of tonsil disease, equally good, and in the long run even better, results may be obtained in a large percentage of cases by measures less radical than those ustually employed at the present time. Out of a multitude of 
examples, take the case of recurring quinsy, for which complete enucleation is done. In this condition it has been found that it is frequently only necessary to thoroughly slit up and shrink the upper lobe of the tonsil. Most quinsies occur in this situation, and the destruction of that part of the tonsil is all sufficient to prevent recurrence. By this method enough of the organ is left to entirely perform its functions, and the tultimate development of quinsy of the lateral columns of the pharynx which follows sometimes complete removal is avoided.

VIII. I do not propose to enter the perennial and monotonous controversy of tonsillotomy versus tonsillectomy. Each operation has its legitimate indications and aims. I do not intend to discuss them. I will only say, in passing, that enucleation of the tonsil (with even the removal of its capsule, if so desired, complete enough for all practical purposes, and this fact should be generally known) practically free from danger, and with equally, and in some instances better results, can be done with the guillotine or one of its modifications. In the majority of cases this procedure will be all sufficient. It is a much simpler method, especially in children, and it is not handicapped by the danger of complete enucleation, with its many accidents and complications, to say nothing of its long roll of unrecorded death. To subject a child to the latter operation, with all that it entails, when we have very much safer and practically just as efficient measures at hand, is, to say the least, bad judgment and unnecessary surgery.

As I see this part of the subject in the light of my own experience, and in the experience and observation of others, the truth is slowly but surely dawning, and at no distant day will irresistibly emerge into recognition, that the socalled complete enucleation-the chief objection to which is that it can never be made complete-except in individuals in whom the organ is totally diseased, is an unnecessary operation in the great majority of cases in which it is at present done, and may be supplanted by many other methods which are perfectly safe and efficient and not open to its many serious objections.

IX. That the tonsil has some important mission to fulfill is furthermore shown from its frequent reappearance after enucleation-a protest, as it were-on the part of nature against the total destruction of its functions, and the vicarious activity of 
the neighboring lymphatic tissues when its physiologic properties cease to exist. This is strikingly shown in the case of quinsy of the lateral columns of the pharynx, before referred to, when the tonsil is rudimentary or gone. In the case, too, of infectious diseases whose poison is eliminated by the throat this compensatory action is most marked. Thus in the malignant epidemic of tonsillitis which occurred last year in Boston, in which the disease was not contagious, did not start from a septic focus in the throat, but was introduced through the food supply (milk), after much constitutional disturbance, the whole tonsillar ring, as Coolidge ${ }^{x}$ expresses it, broke into flame at once. The patients whose tonsils had been removed did not escape the process in the pharyngeal lymphoid tissue, the constitutional symptoms or the cervical adenitis.

$\mathrm{X}$. The tonsils are phonatory organs and play an important part in the mechanism of speech and song. They influence the action of the surrounding muscles and modify the resonance of the mouth. On the other hand, they may be so enlarged as to cripple both these functions, and should, therefore, be removed, such removal being sometimes a gain to the voice of one or more octaves. In tonsillectomy no one can foretell the amount and chatacter of change in the anatomic relations of the parts, no matter how skillful the surgeon is or how skillfully the operation is performed. The adhesions and contractions left after this operation, even in the best of hands, lead often to deplorable changes in the quality and ruin of the singing voice. I should certainly hesitate long before advising such an operation in a great singer or anyone dependent upon the voice as a means of livelihood. The cperation of tonsillectomy is a capital operation, a dangerous operation, and should only be done in a hospital or other place where every facility is at hand to meet the gravest possible emergency. It should only be done by a surgeon skilled in its performance and thoroughly equipped for every accident, and with a mind fully awake to the possible fatality which has so often followed as its result.

XI. One word, again, to those who will fail to grasp the meaning of these remarks. It is not my object to decry in the least degree the many excellent measures which modern ingenuity has devised for the surgical treatment of tonsil affections. No one resorts to them with more alacrity than myself when the necessity for their adoption is apparent. 
It is not my purpose to assail operation for definite and legitimate cause, but to warn against the "busy internist," as Swain so aptly terms him, who is too busy to waste his time with such trifles as differential diagnosis or diagnosis by exclusion, and his accommodating tonsillectomist, who, whether he admits it to himself or not, cares less about the cause of the trouble, as he is in the business for revenue only.

We who are teachers of laryngology should wake up to the responsibilities of our position and see to it that our pupils sha11 not lcave our institutions or postgraduate schools until they are taught, on the one hand, conservatism and moderaw tion in the surgical treatment of the simpler affections of the upper air tract, ancl, on the other hand, thoroughness and completeness when brought into the presence of situations of graver emergency. The problem, though difficult, is not impossible of solution. The curc for the evils I have been discussing is largely educational.

While impressing upon our students the absolute necessity for surgical measures in proper cases, we should at the same time make the langers of their indiscriminate performance fully apparent. In this way only can we be reasonably sure of accomplishing the desired result. The error of first impression derived from teacher and textbook is often difficult of erarication. In the lecture room, in the clinic, in our daily walks with the student, let us make that first impression a good one.

Isut equally if not more responsible for the deplorable state of affairs which exists today in the matter under discussion, are the teacher of internal medicine and the general surgeon. When preeminent authority proclaims in lecture and textbook as indisputable truth the relationship between a host of discases and the tonsil of the child, and advises the removal of the glands as a routine method of procedure, what can we expect of the student whose mind is thus poisoned at the very fountainhear of his medical education by ephemeral theory that masquerades so cheerily in the garb of indestructible fact? How are we to offset the irresponsibility of the responsible? But we hear on all sides-" "Look at the results." Results? Here is a partial list from the practice, not of the ignorant, but of the most experienced and skilled: Death from hemotrhage and shock, development of latent tuber- 
culosis in lungs and adjacent glands, laceration and other serious injuries of the palate and pharyngeal muscles, great contraction of the parts, removal of one barrier of infection, severe infection of the wound, septicemia, troublesome cicatrices, suppurative otitis media and other ear affections, troubles of vision and voice, ruin of the singing voice, emphysema, septic infarct, pneumonia, increased susceptibility to throat disease at the seat of operation, pharyngeal quinsy, and last, but not least, tonsillitis!

Who, may I ask, is in the better position to advise-the surgeon or practitioner, who, without sufficient knowledge, lightly recommends complete enucleation of the tonsils, or those who have devoted their lives to the study of throat conditions and who come in daily contact with its disastrous and often fatal end results? Formerly it was the nasal septum, now it is the tonsil that is the surgical objective of every beginner in laryngology, and a tonsillectomy is usually his first baptism in blood. This operation is done all over the land by operators of all kinds, and, if the truth were known, with great mortality. The amount of reckless surgery done in this field will never be known or chronicled in the pages of medical literature, but it may be found in its abiding place in the book of the recording angel.

Let uts hope that the day is not far distant when not only the profession but the public shall demand that this senseless slaughter be stopped. Is not this day of medical moral preaching and uplifting a fitting one to lift the public out of the atmosphere in which it has been drugged and for the reckless tonsillectomist a proper time to apply the remedy of the referendum and recall.

We are going through today in laryngology what the gynecologist went through years ago. The ovaries were removed then under as little provocation as the tonsils are being taken out today. The socalled "tonsil question" is one of simplicity and comparatively small dimensions when viewed in the light of sanity and common sense, but it has been made to assume formidable proportions by unsound observation and reckless surgery. It has come to a point when it is not only a burning question to the profession, but also to the public. This senseless, ruthless destruction of the tonsil is often so far reaching and enduring in its evil results that it is becoming each day 
a greater menace to the public good. Until we have more definite knowledge concerning the use of the tonsils no one can tell the damage done to the children of the present generation or the influence of wholesale tonsil removal on the children of the next. Whatever a more exact examination of the tonsil may reveal as to its function, I believe it was placed in the throat not with evil, but with good intent-to serve a teleologic rather than a pathologic purpose-that its mission is physiologic, and that it was not designed by nature as a natural, easy and convenient avenue of infection. It is, of course, not open to debate that there are a multitude of conditions that call for partial destruction or more or less complete removal of the tonsils; but radical operation should not be done without definite and sufficient reasons. The tonsil should not be sacrificed any more than any other organ, without convincing evidence that it is the cause of the disease to be removed.

Hasty theory, which sees in destruction of the tonsil the only means of treatment, and which, unmindful of the lymphatic and other anatomic arrangement of the neighboring structures and their physiology, and which, losing sight of the further fact that it is hard, if not impossible, to determine during life that the tonsil is the only avenue of entrance in a given infection, throws differential diagnosis to the winds, should have no part in modern scientific laryngology. When we shall clarify the atmosphere of our ideas in this matter, and when sane authority shall demand a halt, then we will hear less of the massacre of innocent organs and have less frenzied literature on the subject.

\section{LITERATURE.}

1. See T'ransactions, 1911.

2. Transactions of the American Laryngological Association, 1911, p. 263.

3. Archives of Pediatrics, July, 1906.

4. These papers have been collected, the foreign ones translated into English and published in the Laryngoscope, March, 1912.

5. Laryngoscope, March, 1912, p. 180.

6. Boston Medical and Surgical Journal, May $20,1909$.

7. Archiv. f. Laryngologie, 1909, Bd. XXI.

8. Transactions American Laryngological Association, 1911, p. 272. 